\title{
Predicting the Risk of Inferior Alveolar Nerve Injury in Impacted Lower Third Molars Using Panoramic Radiography and Cone Beam Computed Tomography
}

\author{
Abhishek Verma ${ }^{1}$, Stuti Verma ${ }^{2}$, Anushikha Dhankhar ${ }^{3}$, Nitin Kumar Moral ${ }^{4}$, Nidhi Nagar ${ }^{5}$, Ajeet Singh Bhadoria ${ }^{6}$ \\ ${ }^{1}$ Department of Dental Sciences, Shree Bankey Bihari Dental College and Research Centre (SBBDC), Ghaziabad, Uttar \\ Pradesh, India, 2 Department of Hospital Administration, Institute of Liver and Biliary Sciences, New Delhi, India, 3, 6 \\ Department of Community and Family Medicine, All India Institute of Medical Sciences, Rishikesh, Uttarakhand, India, \\ ${ }^{4}$ Department of Dental Sciences, Inderprastha Dental College \& Hospital, Ghaziabad, Uttar Pradesh, India, 5 \\ Department of Dental Sciences, Sharda Dental College, Uttar Pradesh, India.
}

\section{ABSTRACT}

\section{BACKGROUND}

A serious complication of surgical removal of impacted lower third molars is inferior alveolar nerve (IAN) injury. Evaluation of radiographic factors to predict IAN injury using CT and panoramic radiography includes root morphology assessment, follicular sac size, mandibular bone density, inferior alveolar nerve and vessels, condition of the overlying tissues, relation of the impacted tooth with the body and ramus of the mandible and the adjacent teeth. This study was done to evaluate the radiological features of the impacted lower mandibular teeth and their relationship with IAN through panoramic radiography and CT and to assess the most predictable radiological criteria for inferior alveolar nerve injury in impacted third molar surgery.

\section{METHODS}

All the patients indicated for lower third molar extraction were included in the study and pre-operative conventional panoramic radiographs (Planmeca Proline PM 2002 CC, Helsinki, Finland) and CBCT (Kodak CBCT) were taken. Any post-operative nerve injuries detected were followed up after 15 days or 1 month. Fisher's exact test was done to find the association between the outcome variable and explanatory variables.

\section{RESULTS}

Only $11.4 \%(\mathrm{~N}=4)$ of all participants had IAN injury following surgical disimpaction. All the participants with IAN injury showed narrowing of the canal on their preoperative panoramic radiographs and presence of nerve approximation with the tooth in cone beam computed tomography (CBCT) reports $(\mathrm{P}<0.05)$.

\section{CONCLUSIONS}

A statistically significant association exists between IAN injury and nerve exposure, radiographic signs of nerve involvement for panoramic radiograph, level of third molar impaction, and nerve approximation in CBCT.

\section{KEY WORDS}

Inferior Alveolar Nerve Injury, Lower Third Molar Impaction, Panoramic Radiography, CBCT
Corresponding Author: Dr. Ajeet Singh Bhadoria, Associate Professor,

Department of Community and Family Medicine, All India Institute of Medical Sciences, Rishikesh - 249203,

Uttarakhand, India.

E-mail: ajeetsinghbhadoria@gmail.com

DOI: $10.14260 /$ jemds/2021/593

How to Cite This Article:

Verma A, Verma $S$, Dhankhar A, et al. Predicting the risk of inferior alveolar nerve injury in impacted lower third molars using panoramic radiography and cone beam computed tomography. J Evolution Med Dent Sci 2021;10(34):2910-2914, DOI: 10.14260/jemds/2021/593

Submission 20-04-2021,

Peer Review 23-06-2021,

Acceptance 30-06-2021,

Published 23-07-2021.

Copyright (C) 2021 Abhishek Verma et al. This is an open access article distributed under Creative Commons Attribution License [Attribution 4.0 International (CC $B Y 4.0)]$ 


\section{BACKGROUND}

Among the many procedures conducted in oral and maxillofacial surgery, third molar surgery is most common. ${ }^{1}$ Different classifications exist for dental impactions, the most commonly employed being soft tissue, partially bony and full bony impactions. As compared to other teeth, the impaction rate is higher for third molars. Their surgical removal is done to correct or intercept associated pathology. ${ }^{2}$ However, postsurgical complications are common following the procedure. The most common complications of a lower third molar surgery are soft tissue inflammation, pain, alveolar osteitis, trismus, nerve damage (inferior alveolar and lingual nerves), and infections. ${ }^{3}$ The rate of these complications vary from 2.6 $\%$ to $30.9 \%$ and depend upon factors, such as age, sex, overall health condition, level of tooth impaction, experience of the surgeon, smoking and alcohol consumption status, oral hygiene status, presence of comorbid medical conditions, intake of contraceptive medicines among others. ${ }^{3}$ A serious complication of surgical removal of an impacted lower third molar is inferior alveolar nerve (IAN) injury. Low incidence but a large number of lower third molar extractions make the absolute number of IAN injuries significant. ${ }^{4}$ Many studies have been conducted in the past to evaluate radiographic factors to predict IAN injury using CT and panoramic radiography. These evaluations include root morphology assessment, follicular sac size, mandibular bone density, inferior alveolar nerve and vessels, condition of the overlying tissues, impacted tooth and its relation with the body and ramus of the mandible and the adjacent teeth. ${ }^{2}$

The purpose of this study was to use panoramic radiography and CT to assess radiological features of the impacted lower mandibular teeth and their relationship with IAN. It also intended to determine the most predictable radiological criteria for inferior alveolar nerve injury in impacted third molar surgery. To the best of our knowledge, no such study has been previously conducted in a tertiary care hospital in our region.

\section{METHODS}

This was a pilot study conducted between October 2012 and December 2014. Due approval was taken from institutional ethics committee before conducting the study. The study participants included patients who visited the Department of Oral and Maxillofacial Surgery in a tertiary care hospital in Greater Noida, Uttar Pradesh with deep impacted mandibular third molars. All the patients indicated for lower third molar extraction were included in the study and pre-operative conventional panoramic radiographs ("Planmeca Proline PM 2002 CC, Helsinki, Finland") and CBCT ("Kodak CBCT") were taken. The primary predictive criterion were the presence or absence of either one or multiple findings on the preoperative panoramic radiographs, such as interrupted superior cortical line of the inferior alveolar canal wall, canal diversion or narrowing, and darkening of the root. The outcome variable was the presence or absence of inferior alveolar nerve paraesthesia after third molar surgery.

All patients, both males and females, in the age group of 24 - 45 years with recurrent pericoronitis, and with panoramic radiograph demonstrating dark bands on the third molar root or deviation of inferior alveolar root canal or root morphology with a groove or hook were selected. Patients who were medically compromised, had mandibular third molar with associated pathology (such as fracture, cyst, tumour, etc.) and with teeth not in proximity of the inferior alveolar nerve were not selected. Out of all the patients, 35 patients met the inclusion criteria and were included in the study. All the patients were informed in detail about the study and the effects of drugs used. After taking due consent, case history, physical examination and local examination of the impacted tooth to be removed, pre-operative investigations were conducted and findings were recorded using a pre-structured proforma. All the information and data collected during this study were kept confidential.

All the impacted mandibular molars were classified for the type of impaction based on radiographic findings of their relationship with the inferior alveolar canal. Radiographic assessment was done for 7 signs of mandibular nerve proximity with mandibular third molar on OPG. The radiographic features used for classification were darkening, root deflection or narrowing, bifid and dark root apex, interrupted white line of the IAN canal, and canal diversion and narrowing. The surgical procedure was carried out by an oral surgeon with four to five years of experience using standard impaction surgical kit, 3.0 silk suture material, scale, and panoramic radiograph and CBCT.

\section{Surgical Procedure}

Before surgery, all the patients were informed about the potential complications following surgical disimpaction of the impacted mandibular third molar including the risk of damaging the nerve while performing the procedure. The procedure was carried out after locally anaesthetising the area. For superficial impactions, envelope (sulcular) mucoperiosteal flaps and for deeper impactions triangular flaps were raised, which was followed by removal of the vestibular and distal bone. In cases with a higher risk of nerve damage, the impacted tooth was removed sectionally. For sectioning and removal of the bone, tungsten carbide burs (round and fissure) were used (speed of the air - rotor - 35000 - 40,000 rpm). Following the disimpaction, irrigation of the sockets was done with sterile saline solution $(20 \mathrm{~mL})$, which was previously stored at room temperature, and sockets were checked for inferior alveolar nerve exposure both during and after performing focused suction. After manual compression of the socket, single interrupted sutures were placed to close the flaps. A normal saline soaked cotton swab was put on the surgical site under pressure. Post-surgical instructions for wound care were given to each patient. Sutures were removed after one week and patients were examined for signs and symptoms indicating postoperative IAN functional problems. Subjective complaints including but not limited to "numbness in teeth and / or chin", "pins and needles" sensation and objective complaints, for example "light touch", "direction sense", "two - point discrimination" and "pinprick" using the Zuniga (1998) method were recorded.

All patients were asked about altered labial sensation. Any nerve injury detected was followed up after 15 days or 1 month. The affected areas were assessed again using 2 - point discrimination test, pinprick test and light touch test. The 
outcome variable was IAN injury and the selected explanatory variables include age group, sex, and site of impaction, level of impaction, panoramic radiographic signs, CBCT nerve approximation, and nerve exposure. Fisher's exact test was applied to ascertain the association between the outcome variable and explanatory variables.

\section{Statistical Analysis}

Descriptive and inferential statistical analyses were conducted. Categorical variables were presented in number or percentages. A $5 \%$ level of significance was taken to assess the significance of findings. Proportions were compared using the Fisher's exact test with $\mathrm{P}$ value $<0.05$ considered to be statistically significant. SPSS software (version 20.0, IBM Corp. Armonk, New York, United States) was used to analyse data.

\section{RESULTS}

A total of 35 patients participated in the study who underwent pre and post-operative panoramic radiography and CBCT of the impacted lower third molar. Out of these, $80 \%(\mathrm{~N}=28)$ of the patients were males and $20 \%(\mathrm{~N}=7)$ were females. The maximum number of participants $(60 \%, \mathrm{n}=21)$ belonged to the age group of 20 - 25 years followed by $31-35$ years $(20 \%$, $\mathrm{N}=7), 26-30$ years $(14.3 \%, \mathrm{~N}=5), 36-40$ years $(2.9 \% . \mathrm{N}=$ 1) and $41-45$ years $(2.9 \%, N=1)$. Most of the impactions of the lower mandibular third molars were of the right quadrant $(54.3 \%, \mathrm{~N}=19)$ and the rest were of the left quadrant (45.6 $\%, \mathrm{~N}=16)$. Among all the participants, only $11.4 \%(\mathrm{~N}=4)$ had IAN injury following surgical disimpaction. Out of these, $50 \%$ $(\mathrm{N}=2)$ belonged to the age group of $20-25$ years and the other $50 \%(\mathrm{~N}=2)$ to $31-35$ years' age group. Among the participants, $42.9 \%(\mathrm{~N}=15)$ had bony impactions while 57.1 $\%(\mathrm{~N}=20)$ had soft tissue impactions. It was seen that all the participants with post-operative complication of IAN injury had bony impactions whereas no neurological symptoms were reported by those with soft tissue impactions. All the participants with IAN injury showed narrowing of the canal on their pre-operative panoramic radiographs and presence of nerve approximation with the tooth in CBCT reports.

The results of Fisher's exact test revealed no significant association $(\mathrm{P}>0.05)$ between IAN injury and age group (Pearson's $\chi^{2}=3.011, \mathrm{p}=0.556$ ), sex (Pearson's $\chi^{2}=1.129, \mathrm{p}=$ 0.288), and the site (left or right sided) of impaction (Pearson's $\left.\chi^{2}=0.033, p=0.855\right)$. However, the results showed a statistically significant association $(\mathrm{p}<0.05)$ between IAN injury and nerve exposure (Table 1 ), radiographic signs of nerve involvement for panoramic radiograph (Table 4), level of third molar impaction (Table 3), and nerve approximation in CBCT (Table 2).

\begin{tabular}{|c|c|c|c|c|c|}
\hline & & & \multicolumn{2}{|c|}{ Exposure of Nerve } & \multirow[b]{2}{*}{ Total } \\
\hline & & & No & Yes & \\
\hline \multirow{4}{*}{$\begin{array}{l}\text { Nerve } \\
\text { injury }\end{array}$} & \multirow{2}{*}{ No } & Count & 31 & 0 & 31 \\
\hline & & $\%$ within Nerve injury & $100.0 \%$ & $.0 \%$ & $100.0 \%$ \\
\hline & \multirow{2}{*}{ Yes } & Count & 3 & 1 & 4 \\
\hline & & $\%$ within Nerve injury & $75.0 \%$ & $25.0 \%$ & $100.0 \%$ \\
\hline \multirow[b]{2}{*}{ Total } & & Count & 34 & 1 & 35 \\
\hline & & $\%$ within Nerve injury & $97.1 \%$ & $2.9 \%$ & $100.0 \%$ \\
\hline
\end{tabular}

\begin{tabular}{|c|c|c|c|c|c|}
\hline & & & \multicolumn{2}{|c|}{ CBCT Nerve } & \multirow[t]{2}{*}{ Total } \\
\hline & & & No & Yes & \\
\hline \multirow{4}{*}{$\begin{array}{l}\text { Nerve } \\
\text { injury }\end{array}$} & \multirow{2}{*}{ No } & Count & 29 & 2 & 31 \\
\hline & & $\%$ within Nerve injury & $93.5 \%$ & $6.5 \%$ & $100.0 \%$ \\
\hline & \multirow{2}{*}{ Yes } & Count & 0 & 4 & 4 \\
\hline & & $\%$ within Nerve injury & $.0 \%$ & $100.0 \%$ & $100.0 \%$ \\
\hline \multirow{2}{*}{\multicolumn{2}{|c|}{ Total }} & Count & 29 & 6 & 35 \\
\hline & & $\%$ within Nerve injury & $82.9 \%$ & $17.1 \%$ & $100.0 \%$ \\
\hline \multicolumn{6}{|c|}{$\begin{array}{l}\text { Table 2. Frequency Distribution of Nerve Injury } \\
\text { in Patients by Their CBCT Nerve Approximation }\end{array}$} \\
\hline
\end{tabular}

\begin{tabular}{|c|c|c|c|c|c|}
\hline & & & \multicolumn{2}{|c|}{ Impaction } & \multirow{2}{*}{ Total } \\
\hline & & & Bony & Soft & \\
\hline \multirow{4}{*}{ Nerve injury } & \multirow[b]{2}{*}{ No } & Count & 11 & 20 & 31 \\
\hline & & $\begin{array}{c}\% \text { within Nerve } \\
\text { injury }\end{array}$ & $35.5 \%$ & $64.5 \%$ & $100.0 \%$ \\
\hline & \multirow[b]{2}{*}{ Yes } & Count & 4 & 0 & 4 \\
\hline & & $\begin{array}{c}\% \text { within Nerve } \\
\text { injury }\end{array}$ & $100.0 \%$ & $.0 \%$ & $100.0 \%$ \\
\hline \multirow{2}{*}{\multicolumn{2}{|c|}{ Total }} & Count & 15 & 20 & 35 \\
\hline & & $\begin{array}{c}\% \text { within Nerve } \\
\text { injury }\end{array}$ & $42.9 \%$ & $57.1 \%$ & $100.0 \%$ \\
\hline \multicolumn{6}{|c|}{$\begin{array}{c}\text { Table 3. Frequency Distribution of Nerve Injury } \\
\text { in Patients by Their Type of Impaction }\end{array}$} \\
\hline
\end{tabular}

\begin{tabular}{|c|c|c|c|c|c|c|c|c|c|c|}
\hline & & & \multicolumn{7}{|c|}{ Radiographic Signs } & \multirow[b]{2}{*}{ Total } \\
\hline & & & $\begin{array}{l}\text { Darkening of } \\
\text { Root }\end{array}$ & $\begin{array}{l}\text { Narrowing of } \\
\text { Root }\end{array}$ & $\begin{array}{l}\text { Dark and } \\
\text { Bifid Apex of } \\
\text { Root }\end{array}$ & $\begin{array}{l}\text { Deflection of } \\
\text { Root }\end{array}$ & $\begin{array}{l}\text { Interruption of } \\
\text { White Lines of } \\
\text { Canal }\end{array}$ & $\begin{array}{l}\text { Narrowing of } \\
\text { Canal }\end{array}$ & $\begin{array}{l}\text { Diversion of } \\
\text { Canal }\end{array}$ & \\
\hline \multirow{4}{*}{$\begin{array}{l}\text { Nerve } \\
\text { injury }\end{array}$} & \multirow[b]{2}{*}{ No } & Count & 3 & 1 & 1 & 1 & 18 & 5 & 2 & 31 \\
\hline & & $\begin{array}{l}\% \text { within Nerve } \\
\text { injury }\end{array}$ & 9.7 & 3.2 & 3.2 & 3.2 & 58.1 & 16.1 & 6.5 & 100.0 \\
\hline & \multirow[b]{2}{*}{ Yes } & Count & 0 & 0 & 0 & 0 & 0 & 4 & 0 & 4 \\
\hline & & $\begin{array}{l}\% \text { within Nerve } \\
\text { injury }\end{array}$ & 0.0 & 0.0 & 0.0 & $0.0 \%$ & 0.0 & 100.0 & 0.0 & 100.0 \\
\hline \multirow{2}{*}{\multicolumn{2}{|c|}{ Total }} & Count & 3 & 1 & 1 & 1 & 18 & 9 & 2 & 35 \\
\hline & & $\begin{array}{c}\% \text { within Nerve } \\
\text { injury }\end{array}$ & 8.6 & 2.9 & 2.9 & 2.9 & 51.4 & 25.7 & 5.7 & 100.0 \\
\hline
\end{tabular}

\section{DISCUSSION}

A tooth is called impacted when it is partially or completely unerupted. ${ }^{2}$ Among the most common reasons of impaction are abnormal anatomical position, lack of arch space, and physical barriers, such as soft tissue or bone. Though they are considered vestigial, their removal or retainment has been a subject of discussion among doctors for decades. ${ }^{5}$ Multiple factors have to be considered before deciding and planning the disimpaction of an impacted mandibular third molar. ${ }^{6}$ The mandibular third molar is in close approximation with some important anatomical structures, such as IAN, lingual nerve and the mandibular second molar. The deeper the impacted tooth into the bone, more difficult is its extraction and higher are the chances of post-operative complications. ${ }^{7}$ Among the 
various complications, temporary or permanent IAN injury is of most concern to the surgeons, which has an overall incidence of $0.4-13.4 \%{ }^{8}$ To assess the risk of IAN injury, a pre-operative clinical and radiologic assessment using panoramic, computed tomography or CBCT as routine procedures may help in examining the association of the third molar roots and inferior alveolar canal. ${ }^{8}$ On a panoramic radiograph, the radiologic risk predictor signs of close approximation of IAN to third molar include darkening of the root, interruption of the white line, narrowing of the root, narrowing of the canal and dark and bifid root apex. ${ }^{9}$ Although conventional radiography provides good level of nerve injury risk, advancements in medical engineering have provided better alternatives (CT and CBCT) with much clearer images of the prospective surgical areas, which may be considered for routine preoperative assessments for mandibular tooth impactions. ${ }^{10}$

Many studies have been previously conducted to study the role of radiography in pre-operative risk assessment of IAN injury. ${ }^{7-12}$ This study included 35 participants with $80 \%(\mathrm{~N}=$ 28) males and $20 \%(N=7)$ females. The gender distribution is in line with another study conducted by Deshpande et al. and other studies that show male predominance.14,15 Most impactions were reported in the age group of 20 - 25 years. Other studies have reported maximum cases from 15 - 30 years' age group. This is because the eruption time of mandibular third molars is 17 - 21 years. ${ }^{13-16}$ In this study, the association of age group with mandibular third molar impaction was not significant. These findings are in line with the study done by K. Venu Gopal Reddy. ${ }^{13}$ The association of gender was found to be insignificant in this study, which was also reported by Nagaraj et al. ${ }^{17}$

Radiographic assessment of the relationship between IAN and lower third molar helps in assessing the risk of IAN injury. ${ }^{10}$ In our study, narrowing of root canal was found to be the most predictable sign of high risk of IAN injury, which was also confirmed in previously published studies.11,18 In this study, CBCT was found to be better than conventional radiography in assessing the risk of IAN nerve injury in third molar impactions. Similar results were reported by Wang et al. ${ }^{8}$ while Pathak et al. found no significant difference. ${ }^{19}$ Wang et al. also reported a significant association of bony impactions and intraoperative nerve exposure with IAN injury, which was also found in the current study. ${ }^{8}$

The current study showed significant association between IAN injury and level of impaction, radiographic signs, nerve approximation in CBCT reports, and intraoperative nerve exposure, however, the findings need to be confirmed by large sample studies to assess other correlates.

\section{CONCLUSIONS}

Pre-operative panoramic radiography and CBCT assessment can predict the risk of IAN injury in lower third molar impactions, the most predictable features being narrowing of the inferior alveolar canal and proximity of IAN with the impacted tooth. Therefore, a true relationship can be assessed using CBCT technique, which is usually lacking in conventional panoramic radiography. Hence, a CBCT investigation of all the patients indicating high risk of IAN injury on panoramic radiographs should be carefully done to prevent IAN injury following surgical removal of impacted lower third molars.

Data sharing statement provided by the authors is available with the full text of this article at jemds.com.

Financial or other competing interests: None.

Disclosure forms provided by the authors are available with the full text of this article at jemds.com.

\section{REFERENCES}

[1] Deliverska EG, Petkova M. Complications after extraction of impacted third molars-literature review. Journal of IMAB 2016;22(3):1202-11.

[2] Santosh P. Impacted mandibular third molars: review of literature and a proposal of a combined clinical and radiological classification. Ann Med Health Sci Res 2015;5(4):229-34.

[3] Azenha MR, Kato RB, Bueno RBL, et al. Accidents and complications associated to third molar surgeries performed by dentistry students. Oral Maxillofac Surg 2014;18(4):459-64.

[4] Susarla S. Does computed tomographic assessment of inferior alveolar canal cortical integrity predict nerve exposure during third molar surgery? J Oral Maxillofac Surg 2010;68(6):1296-303.

[5] Patel S, Mansuri S, Shaikh F, et al. Impacted mandibular third molars: a retrospective study of 1198 cases to assess indications for surgical removal and correlation with age, sex and type of impaction-a single institutional experience. J Maxillofac Oral Surg 2017;16(1):79-84.

[6] Van Der Linden W, Cleaton-Jones P, Lownie M. Diseases and lesions associated with third molars. Review of 1001 cases. Oral Surg Oral Med Oral Pathol Oral Radiol Endod 1995;79(2):142-5.

[7] Sarikov R, Juodzbalys G. Inferior alveolar nerve injury after mandibular third molar extraction: a literature review. J Oral Maxillofac Res 2014;5(4):e1.

[8] Wang D, Lin T, Wang Y, et al. Radiographic features of anatomic relationship between impacted third molar and inferior alveolar canal on coronal CBCT images: risk factors for nerve injury after tooth extraction. Arch Med Sci 2018;14(3):532-40.

[9] Deshpande P, Guledgud MV, Patil K. Proximity of impacted mandibular third molars to the inferior alveolar canal and its radiographic predictors: a panoramic radiographic study. J Maxillofac Oral Surg 2013;12(2):145-51.

[10] Nakamori K, Tomihara K, Noguchi M. Clinical significance of computed tomography assessment for third molar surgery. World J Radiol 2014;6(7):417-23.

[11] Nayak DS, Raghavan SA, Birur P, et al. Determination of proximity of mandibular third molar to mandibular canal using panoramic radiography and cone-beam computed tomography. J Indian Acad Oral Med Radiol 2017;29(4):273-7.

[12] Costa FWG, Fontenele EHL, Bezerra TP, et al. Correlation between radiographic signs of third molar proximity with inferior alveolar nerve and postoperative occurrence of neurosensory disorders: a prospective, double-blind study. Acta Cir Bras 2013;28(3):221-7. 
[13] Reddy KVG. Distribution of third molar impactions among rural and urban dwellers in the age group of 22-30 years in south india: a comparative study. J Maxillofac Oral Surg 2012;11(3):271-5.

[14] Gupta S, Bhowate RR, Nigam N, et al. Evaluation of impacted mandibular third molars by panoramic radiography. ISRN Dent 2011:2011:406714.

[15] Al-Khateeb TH, Bataineh AB. Pathology associated with impacted mandibular third molars in a group of Jordanians. J Oral Maxillofac Surg 2006;64(11):1598-602.

[16] Knutsson K, Brehmer B, Lysell L, et al. Pathoses associated with mandibular third molars subjected to removal. Oral Surg Oral Med Oral Pathol Oral Radiol Endod 1996;82(1):10-7.
[17] Nagaraj T, Balraj L, Irugu $K$, et al. Radiographic assessment of distribution of mandibular third molar impaction: a retrospective study. Journal of Indian Academy of Oral Medicine and Radiology 2016;28(2):145-9.

[18] Blaeser BF, August MA, Donoff RB, et al. Panoramic radiographic risk factors for inferior alveolar nerve injury after third molar extraction. J Oral Maxillofac Surg 2003;61(4):417-21.

[19] Pathak S, Mishra N, Rastogi MK, et al. Significance of radiological variables studied on orthopantamogram to pridict post-operative inferior alveoler nerve paresthesia after third molar extraction. J Clin Diagn Res 2014;8(5):ZC62-4. 